\title{
Anesthesia For In Utero Repair of Myelomeningocele
}

\author{
Marla Ferschl, M.D. [Assistant Professor], \\ Department of Anesthesia \& Perioperative Care, University of California San Francisco
}

Robert Ball, M.D. [Professor], Departments of Obstetrics, Gynecology \& Reproductive Sciences, University of California San Francisco

Hanmin Lee, M.D. [Professor], and

Department of Surgery, Division of Pediatric Surgery, University of California San Francisco

Mark D. Rollins, M.D., Ph.D. [Associate Professor]

Departments of Anesthesia \& Perioperative Care and Surgery, University of California San

Francisco

\begin{abstract}
Recently published results suggest that prenatal repair of fetal myelomeningocele is a potentially preferable alternative when compared to postnatal repair. In this article, the pathology of myelomeningocele, unique physiologic considerations, perioperative anesthetic management, and ethical considerations of open fetal surgery for prenatal myelomeningocele repair are discussed. Open fetal surgeries have many unique anesthetic issues such as inducing profound uterine relaxation, vigilance for maternal or fetal blood loss, fetal monitoring, and possible fetal resuscitation. Postoperative management, including the requirement for postoperative tocolysis and maternal analgesia are also reviewed. The success of intrauterine myelomeningocele repair relies on a well-coordinated multidisciplinary approach. Fetal surgery is an important topic for anesthesiologists to understand, as the number of fetal procedures is likely to increase as new fetal treatment centers are opened across the United States.
\end{abstract}

\section{Introduction}

Myelomeningocele (Spina bifida) is a non-lethal neural tube defect that currently affects an estimated 5-10 pregnancies per 10,000 in the United States. ${ }^{1}$ Although the incidence of myelomeningocele has decreased with maternal folic acid supplementation, it remains the most common form of spina bifida. A myelomeningocele occurs during the $3^{\text {rd }}$ and $4^{\text {th }}$ weeks of gestation when the embryonic neural plate fails to complete its development and does not close along its length. This results in an open spinal canal with protrusion and exposure of meninges and other neural elements through the defect at birth (Figure 1).

With improved early prenatal screening and option for pregnancy termination, myelomeningocele occurs in approximately 3.4 per 10,000 live births. ${ }^{2}$ The specific cause of myelomeningocele remains unknown, but it is likely multifactorial. The greatest risk factor

Corresponding Author Contact information: Mark D. Rollins, M.D., PhD, Associate Professor, Department of Anesthesia \& Perioperative Care, University of California San Francisco, 513 Parnassus Avenue, Room S-455, Box 0464, San Francisco, CA 94143-0464, Fax: 415-476-1623, Telephone: 415-476-1195, rollinsm@ anesthesia.ucsf.edu.

Work Attributed to: Departments of Anesthesia \& Perioperative Care, Obstetrics and Gynecology, and Surgery University of California at San Francisco, San Francisco, CA

Disclosure of Funding:

Support was provided solely from institutional and/or departmental sources. 
for having a child with a myelomeningocele is a history of a previously affected pregnancy with the same partner. Other risk factors include inadequate folic acid intake, pre-gestational maternal diabetes, and carbemazepine or valproic acid exposure in early pregnancy. Maternal serum alpha-fetoprotein measurement and screening ultrasonography are now used to make a prenatal diagnosis of myelomeningocele in the second trimester of pregnancy. Amniocentesis and fetal magnetic resonance imaging also can be performed to rule out additional anomalies. ${ }^{3}$

Approximately $10 \%$ of babies born with a myelomeningocele die in infancy, and there is a $25 \%$ overall mortality during the first 25 years of life, with the mean age of survival estimated at 30 years. ${ }^{4,5}$ Infants born with myelomeningocele require surgical closure of the defect within the first few days of life and are faced with life-long disabilities (Table 1) including motor dysfunction below the level of the lesion as well as bowel and bladder dysfunction due to loss of sacral nerves. Although the degree of motor and sensory disability is associated with the level of the vertebral defect, the functional level of neurologic deficit is frequently one or more levels higher than the anatomic defect. ${ }^{6}$ Additionally, nearly all infants born with a myelomeningocele have supraspinal neurologic manifestations of the disease process. The Arnold-Chiari Type II malformation is frequently present and includes a small posterior fossa, brain stem abnormalities, and hindbrain herniation (downward displacement of the medulla, cerebellum and fourth ventricle into the spinal canal) resulting in hydrocephalus. The degree of hindbrain herniation does not correlate with severity of symptoms. ${ }^{1}$ Ventriculoperitoneal shunting is required in $85-90 \%$ of children, and despite shunting, some children will have permanent developmental deficits from the Chiari malformation, including central hypoventilation/apnea, oromotor dysfunction, vocal cord dysfunction, and swallowing difficulties. ${ }^{1,7}$ Patients with ventriculoperitoneal shunts need life-long monitoring, and often require surgical revision. ${ }^{3,8}$ Intellect can also be affected in patients with myelomeningocele. Children with spina bifida that do not require shunts are less likely to have learning disabilities compared to those who do, and the average intelligence quotient of those patients with a ventriculoperitoneal shunt is 80 (low-normal). ${ }^{9}$

Serial ultrasound images of fetuses with myelomeningocele suggest that central and peripheral nerve damage is progressive over time..$^{10,11}$ In animal models, fetal closure of a myelomeningocele results in improved neurological function. ${ }^{12}$ This is thought to be due to decreased exposure of neural tissue to the intrauterine environment, resulting in neural tissue preservation. Thus, a two-hit theory of nerve damage has been postulated: the first hit being the failure of the neural tube to form and the second hit being nerve damage caused by exposure to the uterine environment. The option for in utero repair has the potential to decrease neurologic deficits and associated co-morbidities by reducing intrauterine exposure and likely improving function and quality of life in these children. ${ }^{13}$

In this article, anesthetic management issues for open fetal repair of myelomeningocele will be reviewed. Important considerations for the anesthesiologist involved in open fetal procedures, including perioperative implications of maternal and fetal physiology, fetal anesthesia, preoperative evaluation, intraoperative anesthetic techniques, post-operative management, and post-natal concerns will be included. Anesthetic techniques described in this article are similar to those used in other types of open fetal surgery. A discussion of perioperative anesthesia considerations for minimally invasive fetoscopic surgery and other types of in utero procedures can be found elsewhere. ${ }^{14}$

\section{The Development of Fetal Surgery}

Technical advancements of obstetric ultrasonography and improved prenatal diagnosis of anomalies paved the way for development of fetal surgery. They fostered an interest in 
prenatal repair of congenital defects and allowed surgical planning and intervention earlier in gestation. Initial attempts at human fetal surgery began in the 1980s with in utero treatment of urinary obstruction resulting in bilateral hydronephrosis. ${ }^{15}$ With continued improvement in ultrasound resolution, various surgical techniques, monitoring technologies, and anesthetic management, the scope and prevalence of fetal surgery has steadily risen over the past 30 years.

In 1982 the International Fetal Medicine and Surgery Society was established. This group developed criteria for specific malformations and diseases that could be considered for in utero intervention. These criteria focus on severity, diagnosis, previous research, maternal counseling, availability of appropriate resources, and inclusion of a multidisciplinary team. ${ }^{16}$ Two primary types of fetal surgery exist, minimally invasive and open.

Minimally invasive procedures rely on uterine access with needles, trocars, and fetoscopes to perform ultrasound guided or endoscopic interventions. This type of fetal surgery is well established in many locations across the United States and Europe. One of the most common procedures, fetoscopic laser coagulation in twin-to-twin transfusion syndrome, has become the usual treatment modality in many centers, since untreated twins with this condition have a high rate of pregnancy loss. ${ }^{17,18}$ This procedure reduces pregnancy loss with minimal risk to the mother.

Open procedures involve both maternal laparotomy and hysterotomy. Specialized anesthetic techniques are required to maintain uterine relaxation and novel uterine stapling devices are used to minimize blood loss and seal membranes to the myometrium. Open repair is necessary for larger anatomic lesions currently not amenable to fetoscopic repair, such as myelomeningocele and congenital cystic adenomatoid malformation with secondary nonimmune hydrops fetalis (fetal cardiac failure with corresponding edema) not amenable to drainage or shunting. Compared to minimally invasive procedures, an open repair carries a greater chance of morbidity for the mother and the fetus. Similar to living related organ donation, open procedures incur significant maternal risk without direct medical benefit from the surgery. Early studies examining open fetal surgery suggested considerable possibility of preterm labor and uterine dehiscence, as well as an increased risk of preterm delivery and fetal mortality. ${ }^{19,20}$ Additional maternal and fetal risks include not only those from general and regional anesthesia during pregnancy, but also hemorrhage, infection, damage to adjacent organs, pulmonary edema, pulmonary embolism, oligohydramnios, chorioamniotic membrane separation, and need for fetal resuscitation. In a single institution retrospective review of 87 hysterotomies performed for fetal surgery between 1989 and $2003,28 \%$ of mothers had pulmonary edema, $52 \%$ had premature rupture of membranes, $13 \%$ required blood products, $9 \%$ had chorioamnionitis, and the risk of preterm delivery was high and occurred at a mean gestational age of 30 weeks. ${ }^{21}$ Although the occurrence of significant pulmonary edema and hemorrhage has decreased substantially and is now relatively rare, maternal mortality is possible following the procedure. ${ }^{22,23}$ Finally, women who have open procedures require cesarean delivery for this and all future pregnancies secondary to the location of the hysterotomy. The risk of uterine dehiscence or rupture in a subsequent pregnancy is significantly higher following hysterotomy for fetal surgery, compared even to multiple low transverse cesarean sections. Furthermore, compared to women undergoing repeat low transverse cesarean delivery, women with a prior classical incision (such as performed for open procedures) have a higher rate of intensive care unit admission, longer operative time and hospital stay, but similar rates of major maternal and neonatal morbidity associated with subsequent deliveries. ${ }^{24}$ Fetal surgery and the presence of a hysterotomy scar appear to have negligible impact on future fertility ${ }^{25}$, but likely increase the risk of placenta accreta. ${ }^{26}$ Despite the associated risks, open procedures for fetal 
repair have great potential for improving newborn outcome, specifically for the fetus with myelomeningocele. ${ }^{12,13}$

\section{The Management of Myelomeningocele (MOMS) Trial}

Decreased neurological morbidity, and improved motor and sensory function was originally shown in animal models of open fetal myelomeningocele repair. ${ }^{12,27}$ Early studies looking at open in utero repair of myelomeningocele in humans suggested a reduction in hindbrain herniation, but risks to both the fetus and mother were apparent. ${ }^{19,20}$ These findings led to the development and recent publication of an unmasked, randomized, prospective clinical trial examining the potential benefit of open fetal surgery, The Management of Myelomeningocele Study (MOMS). ${ }^{28}$

The MOMS trial had the primary goal of determining the safety and efficacy of repairing neural tube defects in utero when compared to post-natal closure. The primary outcome measures were: 1) composite of fetal or neonatal death; 2) need for ventriculoperitoneal shunt placement by 12 months of age; and 3) composite mental development and motor function at 30 months of age.

Inclusion criteria were: 1) singleton pregnancy; 2) gestational age 19-26 weeks; 3) upper myelomeningocele border of T1-S1; 4) normal karyotype; and 5) maternal body mass index $<35$. The trial was stopped for efficacy after 183 out of 200 patients were enrolled, as it demonstrated fetal surgery reduced the need for ventriclo-peritoneal shunts and also improved motor outcomes at age 30 months. However, open repair was noted to carry risk for both the mother and fetus; preterm birth and partial or complete uterine dehiscence were the most common risks. Maternal and fetal/neonatal complications that were significantly different between the prenatal and postnatal repair groups in the trial are listed in Table 2. Perioperative management of these patients can be challenging, and a multidisciplinary approach is key to optimal patient outcomes and program success. Within the team, the role of the anesthesiologist is to ensure maternal and fetal safety while providing reliable operating conditions for the surgical repair. Consequently, the anesthesiologist must understand the physiologic changes of pregnancy, and how they affect the perioperative management of both the mother and fetus.

\section{Maternal Physiology}

Due to diagnostic considerations and inclusion criteria of the MOMS trial, patients currently undergo open fetal repair at 19-26 weeks gestation. Therefore, the physiologic changes of pregnancy are apparent and significantly affect anesthetic management. Although these changes of pregnancy are detailed elsewhere ${ }^{29,30}$, specific perioperative considerations resulting from these changes have been included in later sections addressing the clinical patient management. These physiologic based considerations are similar to those for pregnant patients undergoing non-obstetric surgery during pregnancy. ${ }^{31,32}$ There is an emphasis on the need for left uterine displacement, potentially challenging airway management, changes in oxygenation and ventilation, increased risk of aspiration, and vigilance in maintaining adequate uterine perfusion and fetal oxygenation.

\section{Fetal Physiology}

A detailed understanding of the fetal cardiovascular system, neurologic system, and uteroplacental interface is essential for anesthetic providers. Without adequate monitoring of fetal physiologic changes, the potential for intraoperative fetal demise is markedly increased. 
Changes in fetal heart rate have significant impact on fetal cardiac output ${ }^{33}$, because the fetal myocardium is less compliant than adult myocardium and far less responsive to changes in preload. ${ }^{34}$ Fetal echocardiographic monitoring and blood flow assessment in the umbilical artery are important in assessing fetal well-being during the perioperative period. Any prolonged decrease in fetal heart rate or significant change in umbilical artery flow dynamics during a fetal procedure should be viewed as an ominous sign. Both absent and reversed umbilical artery diastolic flow are associated with increased perinatal morbidity and mortality. ${ }^{35}$ In the setting of abnormal umbilical artery flow, immediate measures should be taken to improve uterine perfusion, ensure an intact utero-placental interface, and relieve any umbilical or placental compression. In some cases fetal resuscitation may be necessary.

Fetal blood volume increases throughout gestation. Approximately two-thirds of the fetalplacental blood volume is contained within the placenta. ${ }^{36}$ During the second trimester (the usual window for fetal surgery), blood volume has been estimated to be approximately 120 $160 \mathrm{~mL} / \mathrm{kg}$ of fetal body weight ${ }^{37}$, with hemoglobin values ranging approximately 11.5 to $12.5 \mathrm{~g} / \mathrm{dL}$ in otherwise healthy fetuses 18 to 26 weeks gestational age. ${ }^{38}$ Although fetal liver function is not yet mature, coagulation factors are synthesized independent of the maternal circulation. The serum concentrations of these factors increase with gestational age and do not cross the placenta. However, fetal clot formation in response to tissue injury is decreased in comparison to adults.

The fetus is highly dependent on maternal body temperature, unable to thermoregulate, and does not vasoconstrict or shiver in response to decreased core temperature. Induction of general anesthesia, surgical exposure and hysterotomy can all reduce fetal temperature dramatically. Decreases in fetal temperature can lead to bradycardia. ${ }^{39}$ Consequently, maintenance of maternal euthermia, use of warmed fluid for intrauterine irrigation during surgery, and monitoring of both maternal core and amniotic fluid temperatures are all essential to ensure fetal well being.

Fetal oxygen delivery relies on adequate uterine blood flow, with the placenta as the interface between the fetal and maternal circulatory systems. Oxygen transfer to the fetus is dependent on several factors, including the ratio of maternal to fetal blood flow, the oxygen partial pressure gradient, the respective hemoglobin concentrations and affinities, placental diffusing capacity, and the acid-base status of the fetal and maternal blood (Bohr effect). Because the fetal oxyhemoglobin dissociation curve is left-shifted (greater oxygen affinity), the maternal oxyhemoglobin curve is right-shifted (decreased oxygen affinity), and an oxygen partial pressure gradient is present across the placenta, oxygen transfers from the mother to the fetus.

\section{Fetal Analgesia and Anesthesia}

The capability of the fetus to perceive pain is a highly controversial subject. Invasive fetal procedures clearly elicit a stress response ${ }^{40}$, but it is unclear if this response correlates with conscious perception of pain. By 19 weeks gestational age, a fetus can reflexively withdraw from a noxious stimulus without involvement of the cerebral cortex. ${ }^{41}$ Peripheral sensory receptor nociception is transmitted by a reflex arc of afferent fibers that synapse on spinal cord interneurons which then synapse with motor neurons. This stress response can be mediated in the spinal cord, brain stem, or basal ganglia, without cortical involvement.

It is generally accepted that the experience of pain requires higher cortical processing. Pain recognition necessitates intact neural pathways from the periphery through the spinal cord, to the thalamus, the primary sensory cortex, and other higher cortical structures. Cerebral cortical development is complex, and it is difficult to know when thalamic pain fibers reach 
the cortex. Estimates can be made from histological studies of other thalmocortical circuits. Thalamic projections reach the visual subplate at 20-22 weeks ${ }^{42}$, the visual cortex at 23-27 weeks ${ }^{43}$, and the auditory cortical plate at about $26-28$ weeks gestation. ${ }^{44}$ Given this, it is unlikely that fetuses can experience pain before 24 weeks gestation since the cortex must undergo such significant development and establish highly complex neuronal networking.

Based on electroencephalographic studies, cortical activity occurs only $2 \%$ of the time in 24 week gestation fetuses ${ }^{45}$; but by 34 weeks, electrical activity is present $80 \%$ of the time and electroencephalogram patterns become more distinct. ${ }^{46}$ This suggests that even if pain fibers reach the cortex at 24 weeks gestation, the signals may not translate into what we perceive as pain.

Notably, the fetus exhibits pituitary-adrenal, sympathoadrenal, and circulatory stress responses to noxious stimuli as early as 18 weeks gestation. ${ }^{47,48}$ These stress responses are largely mediated in the spinal cord, brain stem, or basal ganglia, rather than the cortex.

Although, they are blunted by opioid administration ${ }^{40}$, reduction of stress hormones are not necessarily indicative of adequate analgesia. ${ }^{49}$ Moreover, these stress responses are different than the multidimensional, subjective phenomenon that we experience as pain.

The long-term consequences of an untreated fetal stress response are unclear, and it is not known definitively when fetuses can experience pain. Therefore, it seems prudent to provide analgesia during fetal surgical procedures. ${ }^{50}$ Providing adequate fetal anesthesia and analgesia inhibits fetal movement during a procedure, prevents the hormonal stress responses associated with poor surgical outcomes in neonates, and may attenuate long-term neurodevelopmental and behavioral concerns. ${ }^{51}$

Fetal anesthesia during open fetal surgery is provided primarily by the placental transfer of maternally administered volatile anesthetics. Intramuscular or intravenous opioid analgesics, such as fentanyl, are also typically administered to the fetus prior to fetal repair. Volatile agents rapidly transfer across the placenta because they are non-ionized, have a low molecular weight, and are highly lipid soluble. Anesthetic gas concentration in the fetus is dependent on both the maternal inspired agent concentration and the duration of anesthetic agent administration to the mother. Exposure of the fetus to volatile anesthetic agents, however, is also not without risk. High concentrations can depress fetal myocardium and lead to progressive fetal acidosis. ${ }^{52}$ At volatile anesthetic concentrations typically required to ensure uterine relaxation ( $>2$ minimum alveolar concentration), animal models have noted significant reductions in maternal cardiac output with a subsequent decrease in uterine blood flow by up to $30 \% .{ }^{53}$ This leads to diminished oxygen delivery and fetal hypoxia. Additionally, animal models have demonstrated increased placental and fetal vascular resistance with halothane use, leading to increased afterload on the fetal heart. ${ }^{54}$ Recently, a retrospective analysis of echocardiographic data from both open fetal surgery cases and exutero intrapartum treatment procedures noted that use of high concentrations of desflurane may cause moderate to severe left ventricular systolic dysfunction in the fetus. ${ }^{55}$

Another concern is that volatile agents may cause neuronal apoptosis in the developing brain. This was initially suggested in 2003, when an anesthetic consisting of midazolam, nitrous oxide, and isoflurane was shown to destroy neurons in the developing brain of 7 dayold rats and cause long-term impairment of brain function. ${ }^{56}$ Further work in primates also demonstrated widespread neurodegeneration in the neonatal period after exposure to isoflurane ${ }^{57}$ It is not currently known if anesthetic agents similarly affect human neonates or fetuses. Several retrospective human studies investigated this area of concern with inconclusive results. A recent retrospective cohort trial noted that a single short anesthetic exposure in children less than 2 years old did not have long term cognitive implications, 
however, exposure to multiple anesthetics was a significant risk factor for development of learning disabilities. ${ }^{58}$ Another retrospective study examined anesthetic exposure and cognitive outcomes in twins, and found no causal relationship between early anesthetic exposure and learning disabilities. ${ }^{59}$ Although there is concern that neurotoxicity might occur in human fetuses or children exposed to anesthetic drugs, current research remains inconclusive about the long-term effects of anesthetic agents on brain function in humans. In 2007, a Food and Drug Administration advisory committee concluded that no change in clinical practice is justifiable based on current data. ${ }^{60,61}$ The cognitive effect of anesthetic exposure on fetuses during fetal surgery remains unknown. Unfortunately the cognitive dysfunction associated with myelomeningocele makes research difficult in this population. Until further human studies are completed that assess the impact of anesthetics on human neural development, maternally administered volatile anesthetics remain the primary agent for fetal anesthesia during open fetal surgery.

\section{Preoperative Assessment}

In order to optimize maternal safety and fetal outcome, the entire multidisciplinary team should be actively involved in counseling, planning, and providing perioperative care, including team members from the disciplines of pediatric surgery, neurosurgery, anesthesiology, maternal fetal medicine, diagnostic imaging, nursing, neonatology, and social work. Regular discussions and multidisciplinary team meetings are crucial to the success of each case. Maternal counseling prior to the procedure should be thorough, unbiased, and accurately reflect the most recent data. In addition to maternal and fetal risks, a detailed discussion of the sequence of perioperative events should be outlined so all questions may be answered. Surgery should not proceed until full informed consent is obtained. If the fetus is at a viable age (i.e. greater than 24 weeks gestation), maternal counseling regarding a detailed resuscitation plan for the neonate should be discussed in the event that an emergent delivery becomes necessary. In the case of a viable fetus, a neonatologist should be immediately available during the procedure.

Ensuring the mother is an appropriate surgical candidate is critical for a successful outcome. As previously detailed, the MOMS trial excluded high-risk maternal candidates and fetuses with other anomalies or abnormal karyotypes. Outcomes of fetal surgery for patients in these excluded categories are unclear, and surgical intervention for these patients is not well established.

Open fetal surgeries have many unique anesthetic issues and a summary of perioperative considerations for myelomeningocele repair is listed in Table 3. A thorough preoperative history and physical by the anesthesiologist is essential. Specific attention to the impact of pregnancy on the mother is sought, including symptoms of recent illness, dyspnea, syncope, dizziness, and gastric reflux. Preoperative laboratory assessment includes a complete blood count and cross match. In addition to matched maternal blood, type O-negative, leukocyte depleted, irradiated, cytomegalovirus negative blood that is also cross-matched against the mother should also be in the operating room, readily available for the fetus, as maternal IgG antibodies cross the placenta. Imaging studies are reviewed for anatomical information regarding the fetal lesion, estimation of fetal weight, determination of other co-existing fetal anomalies that would preclude fetal surgery, and to define exact location of placental borders. The preoperative evaluation should occur a few days before the anticipated surgery date to allow a thorough evaluation, appropriate multidisciplinary planning, and time for the mother to decide if she wants to proceed with surgery. Once a mother has been thoroughly evaluated, determined to be an appropriate candidate, and elects to undergo an open fetal repair, an operative date is planned. Ideally, surgery occurs mid-second trimester, prior to 26 weeks gestation. 
The mother should be appropriately fasted prior to surgery. Before induction of anesthesia, a lumbar epidural is placed for postoperative pain management. An epidural test dose is administered, but the epidural is not activated. Rectal indomethacin is placed for prophylactic tocolysis, and an oral non-particulate antacid is given for aspiration prophylaxis. Preoperative analgesics (narcotics) are not administered routinely for these cases at our institution in order an effort to reduce the degree of hypotension that may be encountered with administration of high concentrations of volatile anesthetics. Given the complex nature of the procedure, all team members should be present and equipment checked prior to entering the operating room.

\section{Intraoperative Anesthetic Considerations}

When all teams are ready to proceed, the patient is brought into the operating room and positioned with left-uterine displacement on the operating table. Sequential compression devices are placed onto the mother's lower extremities to reduce the risk of deep vein thrombosis. Maternal monitors are placed and fetal well being is verified with ultrasound. After preoxygenation and confirmation of surgical readiness, a "rapid-sequence induction" with cricoid pressure and intravenous administration of propofol and succinylcholine is typically performed. Fetal heart rate and umbilical artery blood flow are monitored during induction using ultrasonography. Absent or reverse diastolic flow is considered worrisome and measures are taken to improve fetal perfusion. These include optimization of maternal blood pressure and oxygenation, as well as additional uterine displacement. After confirmation of tracheal intubation, anesthesia is maintained with a volatile agent $(<1$ minimum alveolar concentration) while a urinary bladder catheter is placed, and an ultrasonographer reconfirms fetal position, placental location and a clear path between the planned uterine incision and the fetal spine. A second, large-bore intravenous catheter is placed to facilitate management of the unlikely possibility of sudden blood loss from the hysterotomy. Arterial catheterization for invasive monitoring may be considered, particularly when a nitroglycerine infusion is planned for uterine relaxation. Use of crystalloid during the procedure should be kept to a minimum ( $<2$ liters) to decrease the risk of maternal pulmonary edema following the procedure. ${ }^{62}$ Although fluid administration in the MOMS trial was kept to a minimum, no clinical trials have proven a benefit of this fluid reduction. However, some open fetal surgery centers choose to limit fluids even further $(<500 \mathrm{ml})$. The use of tocolytics such as magnesium sulfate and nitroglycerine increase capillary leak and therefore the risk of maternal pulmonary edema. Although not routinely used at all open fetal centers, colloid administration may also be considered to expand intravascular volume while minimizing total fluids. Drugs for fetal resuscitation, including single-unit doses of atropine $(20 \mathrm{mcg} / \mathrm{kg})$, epinephrine $(10 \mathrm{mcg} / \mathrm{kg})$ and crystalloid $(10 \mathrm{~mL} /$ $\mathrm{kg}$ ) are transferred in a sterile fashion into individually labeled syringes held by the scrub nurse for immediate fetal administration by the surgeon in case of distress. A final discussion amongst all team members (surgical time-out) and administration of maternal prophylactic antibiotics occurs prior to skin incision.

Following surgical incision, the volatile anesthetic agent is increased to provide uterine atony for the surgical procedure. Under normal circumstances, the uterine muscle contracts in response to stimulation. This myometrial contractility is inhibited by calcium sensitive potassium channel modulation by volatile anesthetics. ${ }^{63}$ Consequently, > 2 minimum alveolar concentration of volatile anesthetic is typically attained prior to uterine incision. Uterine relaxation is confirmed by manual palpation by the surgeon and additional volatile agent is titrated as needed. In addition, uterine relaxation may be supplemented with intravenous boluses of nitroglycerine $(50-200 \mathrm{mcg})$, or an intravenous nitroglycerine infusion started to further relax uterine musculature ${ }^{64}$. For circumstances in which a neuraxial anesthetic technique is preferred, a continuous catheter-based anesthetic technique 
can be performed along with an intravenous infusion of nitroglycerine in doses up to 20mcg/ $\mathrm{kg} / \mathrm{min} .{ }^{64}$ Nitroglycerine administration increases the occurrence rate of maternal pulmonary edema during open fetal surgery, perhaps by acting as a nitric oxide donor forming peroxynitrite, which may damage type II alveolar cells and cause lung injury and pulmonary edema via an immune-complex mediated reaction. ${ }^{62}$

During this period of profound anesthesia ( $>2$ minimum alveolar concentration volatile agent), maternal blood pressure must be maintained. Typically the mean arterial pressure is kept within $10 \%$ of maternal baseline. Frequently this requires vasopressor administration. An infusion of phenylephrine provides predictable hemodynamic control while minimizing effects on fetal acid-base status. ${ }^{65}$ Ephedrine or glycopyrolate boluses can also be administered as needed to maintain maternal heart rate and improve cardiac output. ${ }^{66}$ Nondepolarizing muscle relaxants are usually not needed due to the profound depth of anesthesia, but may be used to improve operative conditions. In order to optimize the location of the uterine incision, the intrauterine location and position of the fetus are confirmed with ultrasonography just prior to hysterotomy. A typical ultrasound image and initial exposure of the fetus are shown (Figure 2A).

Following a small uterine incision, a stapling device with absorbable lactomer uterine staples is used to extend the hysterotomy while preventing excessive myometrial bleeding and sealing the membranes to the deciduas and myometrium. ${ }^{67}$ This point in the procedure requires specific vigilance by the anesthesiologist, as the stapling device can misfire, resulting in massive hemorrhage given the profound uterine relaxation. After the hysterotomy is complete, the fetus remains intrauterine, but its back is exposed for repair (Figure 2B). Following the hysterotomy, the table is leveled for the neurosurgical portion of the procedure. An intrauterine infusion of warm crystalloid maintains uterine volume, provides a tamponading pressure to the placental bed, may help prevent cord compression during the procedure, and maintains fetal temperature. Uterine fluid temperature is continuously monitored to prevent fetal hypothermia and associated bradycardia and circulatory compromise ${ }^{39}$.

An intramuscular injection of opioid (fentanyl $10-20 \mathrm{mcg} / \mathrm{kg}$ ) with or without muscle relaxant (e.g. pancuronium or vecuronium $0.1-0.3 \mathrm{mg} / \mathrm{kg}$ ) is administered to the fetus under direct vision (Figure 2C). Alternatively, the injection can be administered prior to hysterotomy using ultrasound guidance. Although anesthetic concentrations of halogenated agent are transferred to the fetus via the placenta, fentanyl further decreases the fetal stress response, and administration of a muscle relaxant can ensure fetal immobility and improve operating conditions. Some centers additionally administer prophylactic intramuscular atropine to the fetus in order to prevent against bradycardia. All three medications may be combined in the same syringe and administered as a single unit dose. An operative microscope is positioned over the exposed myelomeningocele. The neurosurgeon identifies the neural structures and divides the neural placode from the adjacent tissues (Figure 3). Following closure of the dura over the neural placode, the fetal skin may be closed primarily (Figure 4) or with an acellular dermal patch (Figure 5).

Intraoperative fetal monitoring is essential. Surgical manipulation of the uterus and the fetus can significantly reduce placental blood flow and uteroplacental circulation. Direct compression of the maternal inferior vena cava, uterine vasculature, umbilical cord, or fetus can compromise fetal circulation and be catastrophic. Methods of fetal monitoring include continuous fetal pulse oximetry with a sterile probe, intraoperative ultrasound, and fetal echocardiography. Fetal arterial oxygen saturation ranges from $40-70 \%{ }^{68}$, and bradycardia often precedes oxygen desaturation during human fetal surgery. ${ }^{69}$ Umbilical cord arterial flow is periodically assessed to further evaluate fetal well-being and the effects of the 
anesthetic and surgical procedure on both placental and fetal blood flow. Constant vigilance for maternal and fetal bleeding is needed. Both maternal and fetal blood loss can be difficult to quantify, and laboratory tests may be necessary to evaluate hematocrit values. Fetal transfusion should be considered with any significant fetal blood loss, and can be transfused directly into the umbilical vein or by placing a fetal intravenous line.

In the rare case of maternal circulatory collapse, if resuscitation has been unsuccessful after four minutes, the fetus should be delivered emergently. Evacuation of the uterus relieves aortocaval compression, improves the effectiveness of cardiopulmonary resuscitation, and increases maternal and possibly fetal chances for survival. ${ }^{70}$ A neonatologist should be readily available if imminent delivery occurs, and resuscitation should proceed with the current Neonatal Resuscitaiton Program algorithm and guidelines. ${ }^{71}$

As soon as uterine closure begins, a 4 to 6 gram loading dose of magnesium sulfate is administered intravenously over 20 minutes for tocolysis. Magnesium acts on myometrial calcium channels, where it hyperpolarizes the plasma membrane, inhibits myosin light chain kinase activity, and reduces myometrial contractility. ${ }^{72}$ Following the loading dose, an intravenous infusion is started at 1 to 2 grams per hour. It should be noted that magnesium potentiates neuromuscular blockade and muscle relaxant administration should be carefully monitored. Once the magnesium bolus is complete, halogenated anesthetic agents are significantly decreased or discontinued. The epidural is activated, and maternal anesthesia is typically maintained with neuraxial blockade, nitrous oxide, propofol, and/or intravenous fentanyl boluses. This allows adequate time for the volatile agents to be eliminated from maternal tissues and facilitates a safe and timely emergence. Maternal tracheal extubation should only occur after the patient is awake and able to protect her airway.

\section{Postoperative Management}

Postoperative management of fetal surgery patients focuses on tocolysis, fetal monitoring, and maternal analgesia. It is not uncommon for patients to experience early uterine contractions. Uterine activity should be continuously monitored. A magnesium infusion is administered for 24 hours postoperatively. Other tocolytic agents, such as indomethacin, beta adrenergic agents such as terbutaline, and calcium channel blockers such as nifedipine can also be used, and frequently two agents are necessary. Indomethacin can cause premature closure of the ductus arteriosis. Therefore, regular fetal echocardiography must accompany indomethacin use.

Fetal heart rate monitoring should be continuous in the immediate postoperative period, and a plan for emergent delivery should be in place should fetal distress occur. Postoperative concerns besides preterm labor include infection, fetal heart failure, fetal intracranial hemorrhage and fetal demise. Maternal pulmonary edema can also be seen following fetal surgery. If suspected, a chest radiograph can confirm this finding. Although most cases do not require intubation, the time to resolution is variable but often requires multiple days of treatment. ${ }^{62}$ Patients with suspected pulmonary edema should be evaluated for possible critical care admission, positive pressure ventilation, supplemental oxygen, upright positioning and diuretic therapy.

Postoperative analgesia is maintained with an epidural catheter. Intravenous opioids can also be used if necessary, and often a patient controlled analgesia administration device is used for pain control after epidural discontinuation. Effective analgesia might help prevent preterm labor by decreasing plasma oxytocin levels ${ }^{70}$, however opioids can decrease fetal heart rate variability ${ }^{73}$ and make interpretation of the fetal heart rate tracing more challenging. 
Parameters for maternal discharge from the hospital include persistent fetal well-being, adequate amniotic fluid level, appropriate familial support, and a qualified and willing perinatology practice in the patient's home area. We recommend that patients remain in the local area, in close proximity to the fetal surgery treatment facility for at least two weeks postoperatively. During outpatient care, amniotic fluid levels, integrity of fetal membranes, fetal growth and ventricular size, fetal heart tracing and non-stress tests, as well as cervical length are assessed weekly. A course of steroids can be administered to improve fetal lung maturity secondary to concerns of premature delivery. Due to the need for cesarean delivery and classical hysterotomy, delivery occurs at 37 weeks gestation. Patients presenting to local hospitals following fetal surgery should be considered high risk, as their often incompletely healed hysterotomy scar can increase the chance of uterine rupture, as well as emergent cesarean section. All patients undergoing cesarean delivery following open fetal surgery should have large bore intravenous access, as well as be typed and crossed for four units of packed red blood cells.

\section{Postnatal Considerations}

Following birth, neonates that have undergone fetal myelomeningocele repair need a full evaluation. Consults from neurosurgery, pediatrics, orthopedics and urology should be obtained. Head ultrasound assessing ventricular size and need for shunting should be performed as needed. Renal ultrasound, urologic dynamic studies, and hip ultrasound should be done per consultants request. The lumbar repair site should also be evaluated. Patients with primary closure often are well-healed (Figure 4); patients with patches may have small skin defects (Figure 5). These defects usually close without intervention after two to three weeks. Latex precautions should be observed. Prior to hospital discharge, appropriate follow up in a spina bifida clinic should be arranged.

\section{Ethical and Legal Considerations}

The MOMS trial showed benefit for the child if myelomeningocele closure occurs in utero. However, many babies receiving prenatal intervention were born prematurely (average gestational age at birth 34 weeks) in comparison to babies who were operated on postnatally (average gestational age at birth 37 weeks). The risks associated with prematurity should not be overlooked. Morbidities such as respiratory distress syndrome, necrotizing enterocolitis and intraventricular hemorrhage have life-long implications for the child and carry substantial $\operatorname{cost}^{74}$.

There is some debate as to whether the results of the MOMS trial are applicable to fetal intervention performed at centers outside the trial institutions. Only $15 \%$ of maternal candidates wanting fetal intervention met enrollment criteria and the length of the trial spanned 8 years of surgical experience. Outcomes from new institutions with little experience and patients outside the inclusion criteria are likely to have less favorable results with increased morbidity. ${ }^{75}$ To address this concern, a bioethics committee from the American College of Obstetricians and Gynecologists and the American Academy of Pediatrics provided recommendations for centers offering fetal repair of myelomeningocele. ${ }^{76}$ This committee noted the need for a thorough informed consent process, appropriate safeguards in the conduct of maternal-fetal research, the need for a multidisciplinary approach, and the need for collaborative research networks. Despite the cost of the randomized controlled trials, and given the concerns about transferring the results to new institutions, it is clear that initiation of clinical research in fetal surgery is necessary to appropriately balance the unique risks and benefits of future advancements.

A recently published European study compared 19 fetuses undergoing intrauterine endoscopic myelomeningocele repair to matched controls. ${ }^{77}$ An extraordinarily high 
complication rate of both mothers and fetuses was noted. Of the 19 enrolled, 3 fetuses died during the procedure and another 3 cases were stopped secondary to uncontrolled bleeding caused by the procedure. Although fetal repair was associated with spinal segmental neuroprotection, it resulted in significantly more complications. It was concluded by the authors that, "before considering clinical implementation of fetal endoscopic myelomeningocele closure as standard care, the frequency of complications should be appropriately reduced and results assessed in larger groups over a longer period of time. ${ }^{77 "}$ Ethical considerations regarding the principal concept of primum non nocere argues that until a procedure is appropriately tested in animals it is unethical to pursue in human trials. $^{78,79}$

As the prominence of fetal surgery increases, legal questions will arise ${ }^{80}$ For example, a pregnant patient can currently consent to fetal surgery, but if its efficacy becomes more clear, will she legally be allowed to decline intervention? Are physicians morally or legally obligated to inform women about the availability of fetal surgery? If a patient were enrolled in a trial early in gestation and randomized to a nonfetal treatment group, what are the implications if she desires termination? Can a patient be held to an agreement of nontermination for study enrollment? These questions are challenging ones that will need to be addressed as fetal surgery further develops.

\section{Conclusions}

Anesthesia for fetal surgery represents a relatively young and expanding specialty within the field of anesthesiology. Open fetal repair incorporates elements from anesthetic management of traditional cesarean delivery, ex-utero intrapartum therapy procedures, nonobstetric surgery during pregnancy, and pediatric surgery. The moratorium on prenatal myelomeningocele repair has been lifted following the MOMS publication, and other centers are now exploring the possibility of opening fetal treatment centers of their own. Meanwhile, additional data analysis from the trial is ongoing, and long-term outcomes of these patients needs to be assessed. Currently, open fetal repair is rarely performed in Europe $^{81}$, this will also likely change. It is important that anesthesiologists appreciate maternal and fetal physiology to better care for these patients in the surgical and postsurgical setting.

More work is needed to establish the effect of volatile anesthetic agents on the developing fetal brain, and help understand whether early anesthetic exposure as a fetus has an effect on postnatal cognitive function. Other future considerations include the role of anesthesia subspecialty training, and perhaps even development of standard guidelines for fetal anesthesia. Appropriate patient selection and timing of the intervention needs to be better established. Other indications for open fetal surgery exist, including prenatal intervention for congenital cystic adenomatoid malformations, congenital heart disease and sacrococcygeal teratomas. Certainly, there is a need for further randomized, controlled trials in both animals and humans looking at outcomes from fetal intervention. Advances in fetal therapy will require careful assessment of fetal benefit as well as fetal and maternal risk, as fetal surgery remains one of only a few procedures that pose morbidity and mortality to two patients.

\section{References}

1. Shaer CM, Chescheir N, Schulkin J. Myelomeningocele: A review of the epidemiology, genetics, risk factors for conception, prenatal diagnosis, and prognosis for affected individuals. Obstet Gynecol Surv. 2007; 62:471-9. [PubMed: 17572919]

2. Boulet SL, Yang Q, Mai C, Kirby RS, Collins JS, Robbins JM, Meyer R, Canfield MA, Mulinare J. Trends in the postfortification prevalence of spina bifida and anencephaly in the United States. Birth Defects Res A Clin Mol Teratol. 2008; 82:527-32. [PubMed: 18481813] 
3. Mitchell LE, Adzick NS, Melchionne J, Pasquariello PS, Sutton LN, Whitehead AS. Spina bifida. Lancet. 2004; 364:1885-95. [PubMed: 15555669]

4. Thompson DN. Postnatal management and outcome for neural tube defects including spina bifida and encephalocoeles. Prenat Diagn. 2009; 29:412-9. [PubMed: 19194999]

5. Davis BE, Daley CM, Shurtleff DB, Duguay S, Seidel K, Loeser JD, Ellenbogan RG. Long-term survival of individuals with myelomeningocele. Pediatr Neurosurg. 2005; 41:186-91. [PubMed: 16088253]

6. Rintoul NE, Sutton LN, Hubbard AM, Cohen B, Melchionni J, Pasquariello PS, Adzick NS. A new look at myelomeningoceles: Functional level, vertebral level, shunting, and the implications for fetal intervention. Pediatrics. 2002; 109:409-13. [PubMed: 11875133]

7. Stein SC, Schut L. Hydrocephalus in myelomeningocele. Childs Brain. 1979; 5:413-9. [PubMed: 456113]

8. Hunt GM. The median survival time in open spina bifida. Dev Med Child Neurol. 1997; 39:568. [PubMed: 9295857]

9. Oakeshott P, Hunt GM. Long-term outcome in open spina bifida. Br J Gen Pract. 2003; 53:632-6. [PubMed: 14601340]

10. Korenromp MJ, van Gool JD, Bruinese HW, Kriek R. Early fetal leg movements in myelomeningocele. Lancet. 1986; 1:917-8. [PubMed: 2870386]

11. Sival DA, Begeer JH, Staal-Schreinemachers AL, Vos-Niel JM, Beekhuis JR, Prechtl HF. Perinatal motor behaviour and neurological outcome in spina bifida aperta. Early Hum Dev. 1997; 50:2737. [PubMed: 9467691]

12. Julia V, Sancho MA, Albert A, Conill J, Martinez A, Grande C, Morales L. Prenatal covering of the spinal cord decreases neurologic sequelae in a myelomeningocele model. J Pediatr Surg. 2006; 41:1125-9. [PubMed: 16769346]

13. Fichter MA, Dornseifer U, Henke J, Schneider KT, Kovacs L, Biemer E, Bruner J, Adzick NS, Harrison MR, Papadopulos NA. Fetal spina bifida repair--current trends and prospects of intrauterine neurosurgery. Fetal Diagn Ther. 2008; 23:271-86. [PubMed: 18417993]

14. Rosen, M. Anesthesia for Fetal Surgery and Other Intrauterine Procedures, Chestnut's Obstetric Anesthesia: Principles and Practice. 4. Chestnut, DH.; Polley, LS.; Tsen, LC.; Wong, CA., editors. Philadelphia: Elsevier Inc; 2009. p. 123-40.

15. Harrison MR, Golbus MS, Filly RA, Callen PW, Katz M, de Lorimier AA, Rosen M, Jonsen AR. Fetal surgery for congenital hydronephrosis. N Engl J Med. 1982; 306:591-3. [PubMed: 7057815]

16. Harrison MR, Filly RA, Golbus MS, Berkowitz RL, Callen PW, Canty TG, Catz C, Clewell WH, Depp R, Edwards MS, Fletcher JC, Frigoletto FD, Garrett WJ, Johnson ML, Jonsen A, De Lorimier AA, Liley WA, Mahoney MJ, Manning FD, Meier PR, Michejda M, Nakayama DK, Nelson L, Newkirk JB, Pringle K, Rodeck C, Rosen MA, Schulman JD. Fetal treatment 1982. N Engl J Med. 1982; 307:1651-2. [PubMed: 7144864]

17. Chalouhi GE, Essaoui M, Stirnemann J, Quibel T, Deloison B, Salomon L, Ville Y. Laser therapy for twin-to-twin transfusion syndrome (TTTS). Prenat Diagn. 2011; 31:637-46. [PubMed: 21660997]

18. Senat MV, Deprest J, Boulvain M, Paupe A, Winer N, Ville Y. Endoscopic laser surgery versus serial amnioreduction for severe twin-to-twin transfusion syndrome. N Engl J Med. 2004; 351:136-44. [PubMed: 15238624]

19. Tulipan N, Bruner JP, Hernanz-Schulman M, Lowe LH, Walsh WF, Nickolaus D, Oakes WJ. Effect of intrauterine myelomeningocele repair on central nervous system structure and function. Pediatr Neurosurg. 1999; 31:183-8. [PubMed: 10705927]

20. Sutton LN, Adzick NS, Bilaniuk LT, Johnson MP, Crombleholme TM, Flake AW. Improvement in hindbrain herniation demonstrated by serial fetal magnetic resonance imaging following fetal surgery for myelomeningocele. JAMA. 1999; 282:1826-31. [PubMed: 10573273]

21. Golombeck K, Ball RH, Lee H, Farrell JA, Farmer DL, Jacobs VR, Rosen MA, Filly RA, Harrison MR. Maternal morbidity after maternal-fetal surgery. Am J Obstet Gynecol. 2006; 194:834-9. [PubMed: 16522421]

22. Wu D, Ball RH. The maternal side of maternal-fetal surgery. Clin Perinatol. 2009; 36:247-53. viii. [PubMed: 19559319] 
23. Bruner JP, Tulipan NB, Richards WO, Walsh WF, Boehm FH, Vrabcak EK. In utero repair of myelomeningocele: A comparison of endoscopy and hysterotomy. Fetal Diagn Ther. 2000; 15:838. [PubMed: 10720871]

24. Bakhshi T, Landon MB, Lai Y, Spong CY, Rouse DJ, Leveno KJ, Varner MW, Caritis SN, Meis PJ, Wapner RJ, Sorokin Y, Miodovnik M, Carpenter M, Peaceman AM, O’Sullivan MJ, Sibai BM, Langer O, Thorp JM, Mercer BM. Maternal and neonatal outcomes of repeat cesarean delivery in women with a prior classical versus low transverse uterine incision. Am J Perinatol. 2010; 27:7916. [PubMed: 20458666]

25. Farrell JA, Albanese CT, Jennings RW, Kilpatrick SJ, Bratton BJ, Harrison MR. Maternal fertility is not affected by fetal surgery. Fetal Diagn Ther. 1999; 14:190-2. [PubMed: 10364673]

26. Clark EA, Silver RM. Long-term maternal morbidity associated with repeat cesarean delivery. Am J Obstet Gynecol. 2011; 205:S2-10. [PubMed: 22114995]

27. Sutton LN. Fetal surgery for neural tube defects. Best Pract Res Clin Obstet Gynaecol. 2008; 22:175-88. [PubMed: 17714997]

28. Adzick NS, Thom EA, Spong CY, Brock JW 3rd, Burrows PK, Johnson MP, Howell LJ, Farrell JA, Dabrowiak ME, Sutton LN, Gupta N, Tulipan NB, D’Alton ME, Farmer DL. A randomized trial of prenatal versus postnatal repair of myelomeningocele. N Engl J Med. 2011; 364:993-1004. [PubMed: 21306277]

29. Cheek, TG.; Gutsche, BB. Maternal Physiologic Alterations, Shnider and Levinson's Anesthesia for Obstetrics. 4. Hughes, SC.; Levinson, G.; Rosen, MA.; Shnider, SM., editors. Philadelphia: Lippincott Williams \& Wilkins; 2002. p. 3-18.

30. Gaiser, R. Physiologic Changes of Pregnancy, Chestnut's Obstetric Anesthesia: Principles and Practice. 4. Chestnut, DH.; Polley, LS.; Tsen, LC.; Wong, CA., editors. Philadelphia: Elsevier Inc; 2009. p. 15-36.

31. Van de Velde, M. Nonobstetric surgery during pregnancy, Chestnut's obstetric anesthesia principlesand practice. 4. Chestnut, DH., editor. Philadelphia: Mosby Elsevier; 2009. p. 337-60.

32. Cheek TG, Baird E. Anesthesia for nonobstetric surgery: Maternal and fetal considerations. Clin Obstet Gynecol. 2009; 52:535-45. [PubMed: 20393407]

33. Rychik J. Fetal cardiovascular physiology. Pediatr Cardiol. 2004; 25:201-9. [PubMed: 15360113]

34. Gilbert RD. Control of fetal cardiac output during changes in blood volume. Am J Physiol. 1980; 238:H80-6. [PubMed: 7356036]

35. Vasconcelos RP, Brazil Frota Aragao JR, Costa Carvalho FH, Salani Mota RM, de Lucena Feitosa FE, Alencar Junior CA. Differences in neonatal outcome in fetuses with absent versus reverse enddiastolic flow in umbilical artery Doppler. Fetal Diagn Ther. 2010; 28:160-6. [PubMed: 20847548]

36. Yao AC, Moinian M, Lind J. Distribution of blood between infant and placenta after birth. Lancet. 1969; 2:871-3. [PubMed: 4186454]

37. Morris JA, Hustead RF, Robinson RG, Haswell GL. Measurement of fetoplacental blood volume in the human previable fetus. Am J Obstet Gynecol. 1974; 118:927-34. [PubMed: 4818425]

38. Forestier F, Daffos F, Galacteros F, Bardakjian J, Rainaut M, Beuzard Y. Hematological values of 163 normal fetuses between 18 and 30 weeks of gestation. Pediatr Res. 1986; 20:342-6. [PubMed: 3703624]

39. Aboud E, Neales K. The effect of maternal hypothermia on the fetal heart rate. Int J Gynaecol Obstet. 1999; 66:163-4. [PubMed: 10468340]

40. Fisk NM, Gitau R, Teixeira JM, Giannakoulopoulos X, Cameron AD, Glover VA. Effect of direct fetal opioid analgesia on fetal hormonal and hemodynamic stress response to intrauterine needling. Anesthesiology. 2001; 95:828-35. [PubMed: 11605920]

41. Lee SJ, Ralston HJ, Drey EA, Partridge JC, Rosen MA. Fetal pain: A systematic multidisciplinary review of the evidence. JAMA. 2005; 294:947-54. [PubMed: 16118385]

42. Hevner RF. Development of connections in the human visual system during fetal mid-gestation: A DiI-tracing study. J Neuropathol Exp Neurol. 2000; 59:385-92. [PubMed: 10888368]

43. Kostovic I, Rakic P. Development of prestriate visual projections in the monkey and human fetal cerebrum revealed by transient cholinesterase staining. J Neurosci. 1984; 4:25-42. [PubMed: 6693940] 
44. Krmpotic-Nemanic J, Kostovic I, Kelovic Z, Nemanic D, Mrzljak L. Development of the human fetal auditory cortex: growth of afferent fibres. Acta Anat (Basel). 1983; 116:69-73. [PubMed: 6858605]

45. Clancy, RR.; Bergqvist, A.; Dlugos, DJ. Neonatal electroencephalography, Current Practice of Clinical Electroencephalography. 3. Ebersole, JS.; Pedley, TA., editors. Philadelphia: Lippincott Williams \& Wilkins; 2003. p. 160-234.

46. Torres F, Anderson C. The normal EEG of the human newborn. J Clin Neurophysiol. 1985; 2:89103. [PubMed: 3916842]

47. Teixeira J, Fogliani R, Giannakoulopoulos X, Glover V, Fisk NM. Fetal haemodynamic stress response to invasive procedures. Lancet. 1996; 347:624. [PubMed: 8596359]

48. Gitau R, Fisk NM, Teixeira JM, Cameron A, Glover V. Fetal hypothalamic-pituitary-adrenal stress responses to invasive procedures are independent of maternal responses. J Clin Endocrinol Metab. 2001; 86:104-9. [PubMed: 11231985]

49. Derbyshire SW. Locating the beginnings of pain. Bioethics. 1999; 13:1-31. [PubMed: 11657057]

50. Glover V, Fisk N. Do fetuses feel pain? We don't know; better to err on the safe side from midgestation (Letter). BMJ. 1996; 313:796. [PubMed: 8842075]

51. Anand KJ, Hickey PR. Pain and its effects in the human neonate and fetus. N Engl J Med. 1987; 317:1321-9. [PubMed: 3317037]

52. Biehl DR, Yarnell R, Wade JG, Sitar D. The uptake of isoflurane by the foetal lamb in utero: Effect on regional blood flow. Can Anaesth Soc J. 1983; 30:581-6. [PubMed: 6640394]

53. Palahniuk RJ, Shnider SM. Maternal and fetal cardiovascular and acid-base changes during halothane and isoflurane anesthesia in the pregnant ewe. Anesthesiology. 1974; 41:462-72. [PubMed: 4429215]

54. Sabik JF, Assad RS, Hanley FL. Halothane as an anesthetic for fetal surgery. J Pediatr Surg. 1993; 28:542-6. discussion 546-7. [PubMed: 8483067]

55. Boat A, Mahmoud M, Michelfelder EC, Lin E, Ngamprasertwong P, Schnell B, Kurth CD, Crombleholme TM, Sadhasivam S. Supplementing desflurane with intravenous anesthesia reduces fetal cardiac dysfunction during open fetal surgery. Paediatr Anaesth. 2010; 20:748-56. [PubMed: 20670239]

56. Jevtovic-Todorovic V, Hartman RE, Izumi Y, Benshoff ND, Dikranian K, Zorumski CF, Olney JW, Wozniak DF. Early exposure to common anesthetic agents causes widespread neurodegeneration in the developing rat brain and persistent learning deficits. J Neurosci. 2003; 23:876-82. [PubMed: 12574416]

57. Brambrink AM, Evers AS, Avidan MS, Farber NB, Smith DJ, Zhang X, Dissen GA, Creeley CE, Olney JW. Isoflurane-induced neuroapoptosis in the neonatal rhesus macaque brain. Anesthesiology. 2010; 112:834-41. [PubMed: 20234312]

58. Flick RP, Katusic SK, Colligan RC, Wilder RT, Voigt RG, Olson MD, Sprung J, Weaver AL, Schroeder DR, Warner DO. Cognitive and behavioral outcomes after early exposure to anesthesia and surgery. Pediatrics. 2011; 128:e1053-61. [PubMed: 21969289]

59. Bartels M, Althoff RR, Boomsma DI. Anesthesia and cognitive performance in children: no evidence for a causal relationship. Twin Res Hum Genet. 2009; 12:246-53. [PubMed: 19456216]

60. Stratmann G. Review article: Neurotoxicity of anesthetic drugs in the developing brain. Anesth Analg. 2011; 113:1170-9. [PubMed: 21965351]

61. Mellon RD, Simone AF, Rappaport BA. Use of anesthetic agents in neonates and young children. Anesth Analg. 2007; 104:509-20. [PubMed: 17312200]

62. DiFederico EM, Burlingame JM, Kilpatrick SJ, Harrison M, Matthay MA. Pulmonary edema in obstetric patients is rapidly resolved except in the presence of infection or of nitroglycerin tocolysis after open fetal surgery. Am J Obstet Gynecol. 1998; 179:925-33. [PubMed: 9790372]

63. Kafali H, Kaya T, Gursoy S, Bagcivan I, Karadas B, Sarioglu Y. The role of K(+) channels on the inhibitor effect of sevoflurane in pregnant rat myometrium. Anesth Analg. 2002; 94:174-8. [PubMed: 11772823]

64. Rosen MA, Andreae MH, Cameron AG. Nitroglycerin for fetal surgery: Fetoscopy and ex utero intrapartum treatment procedure with malignant hyperthermia precautions. Anesth Analg. 2003; 96:698-700. [PubMed: 12598248] 
65. Ngan Kee WD, Lee A, Khaw KS, Ng FF, Karmakar MK, Gin T. A randomized double-blinded comparison of phenylephrine and ephedrine infusion combinations to maintain blood pressure during spinal anesthesia for cesarean delivery: The effects on fetal acid-base status and hemodynamic control. Anesth Analg. 2008; 107:1295-302. [PubMed: 18806043]

66. Habib AS. Review article: A review of the impact of phenylephrine administration on maternal hemodynamics and maternal and neonatal outcomes in women undergoing cesarean delivery under spinal anesthesia. Anesth Analg. 2012; 114:377-90. [PubMed: 22104076]

67. Bond SJ, Harrison MR, Slotnick RN, Anderson J, Flake AW, Adzick NS. Cesarean delivery and hysterotomy using an absorbable stapling device. Obstet Gynecol. 1989; 74:25-8. [PubMed: 2733936]

68. Johnson N, Johnson VA, Fisher J, Jobbings B, Bannister J, Lilford RJ. Fetal monitoring with pulse oximetry. Br J Obstet Gynaecol. 1991; 98:36-41. [PubMed: 1998630]

69. Izumi A, Minakami H, Sato I. Fetal heart rate decelerations precede a decrease in fetal oxygen content. Gynecol Obstet Invest. 1997; 44:26-31. [PubMed: 9251950]

70. Santolaya-Forgas J, Romero R, Mehendale R. The effect of continuous morphine administration on maternal plasma oxytocin concentration and uterine contractions after open fetal surgery. $\mathrm{J}$ Matern Fetal Neonatal Med. 2006; 19:231-8. [PubMed: 16854697]

71. Kattwinkel J, Perlman JM, Aziz K, Colby C, Fairchild K, Gallagher J, Hazinski MF, Halamek LP, Kumar P, Little G, McGowan JE, Nightengale B, Ramirez MM, Ringer S, Simon WM, Weiner GM, Wyckoff M, Zaichkin J. Part 15: Neonatal resuscitation: 2010 American Heart Association Guidelines for Cardiopulmonary Resuscitation and Emergency Cardiovascular Care. Circulation. 2010; 122:S909-19. [PubMed: 20956231]

72. Mizuki J, Tasaka K, Masumoto N, Kasahara K, Miyake A, Tanizawa O. Magnesium sulfate inhibits oxytocin-induced calcium mobilization in human puerperal myometrial cells: Possible involvement of intracellular free magnesium concentration. Am J Obstet Gynecol. 1993; 169:1349. [PubMed: 8333439]

73. Smith CV, Rayburn WF, Allen KV, Bane TM, Livezey GT. Influence of intravenous fentanyl on fetal biophysical parameters during labor. J Matern Fetal Med. 1996; 5:89-92. [PubMed: 8796775]

74. Meadow W, Cohen-Cutler S, Spelke B, Kim A, Plesac M, Weis K, Lagatta J. The Prediction and Cost of Futility in the NICU. Acta Paediatr. 2012; 101:397-402. [PubMed: 22150563]

75. Danzer E, Johnson MP, Adzick NS. Fetal surgery for myelomeningocele: Progress and perspectives. Dev Med Child Neurol. 2011; 54:8-14. [PubMed: 21745203]

76. Maternal-fetal intervention and fetal care centers. Pediatrics. 2011; 128:e473-8. [PubMed: 21788223]

77. Verbeek RJ, Heep A, Maurits NM, Cremer R, Hoving EW, Brouwer OF, van der Hoeven JH, Sival DA. Fetal endoscopic myelomeningocele closure preserves segmental neurological function. Dev Med Child Neurol. 2012; 54:15-22. [PubMed: 22126123]

78. Chervenak FA, McCullough LB. Ethics of fetal surgery. Clin Perinatol. 2009; 36:237-46. vii-viii. [PubMed: 19559318]

79. Shurtleff D. Fetal endoscopic myelomeningocele repair. Dev Med Child Neurol. 2012; 54:4-5. [PubMed: 22126087]

80. Dickens BM, Cook RJ. Legal and ethical issues in fetal surgery. Int J Gynaecol Obstet. 2011; 115:80-3. [PubMed: 21839453]

81. Deprest JA, Done E, Van Mieghem T, Gucciardo L. Fetal surgery for anesthesiologists. Curr Opin Anaesthesiol. 2008; 21:298-307. [PubMed: 18458545] 

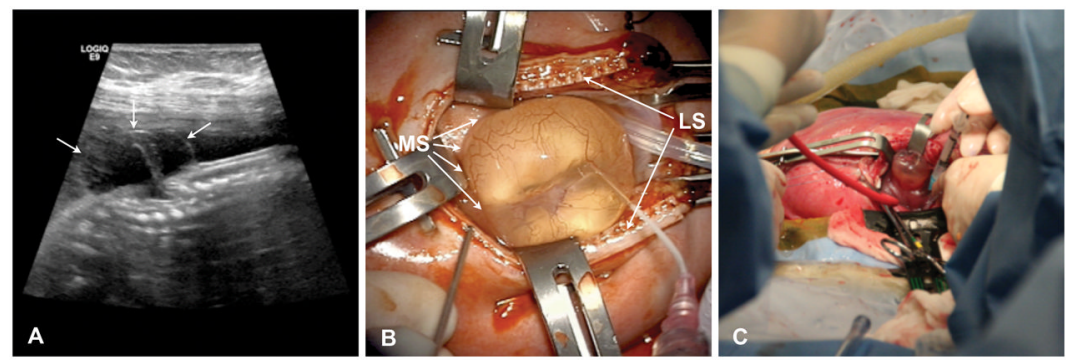

Figure 1.

Term neonate with large lumbar myelomeningocele. 

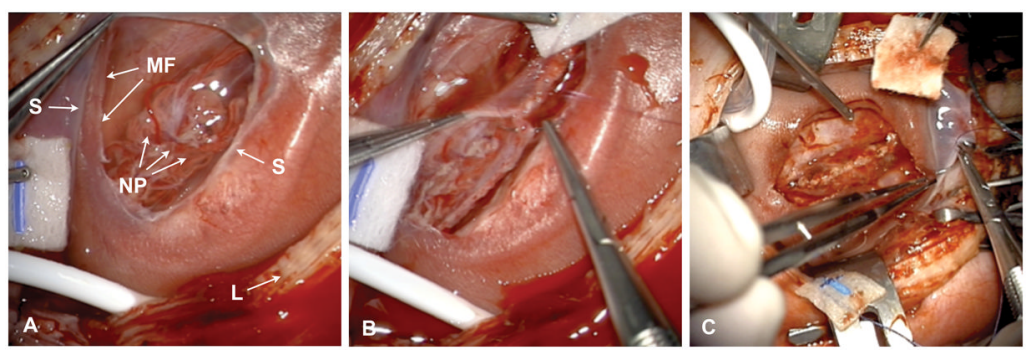

Figure 2. Operative Preparation for Open Myelomeningocele Repair

(A): Prior to uterine incision, the myelomeningocele is identified using ultrasound and positioned for repair. Arrows note sac border. This fetus has a L2 defect and is at a gestational age of 23 weeks. (B): The myelomeningocele sac is exposed for open surgical repair following uterine incision with use of lactomer uterine staples to prevent uterine wall hemorrhage. Profound uterine relaxation is achieved using high ( $>2$ minimum alveolar concentration) inhalational anesthetic agent. Arrows labeled (MS) note myelomeningocele sac border and arrows labeled (LS) note lactomer staples. (C): An intramuscular muscle relaxant and opioid are injected into the fetus by the surgeon to ensure fetal immobility during the repair. 

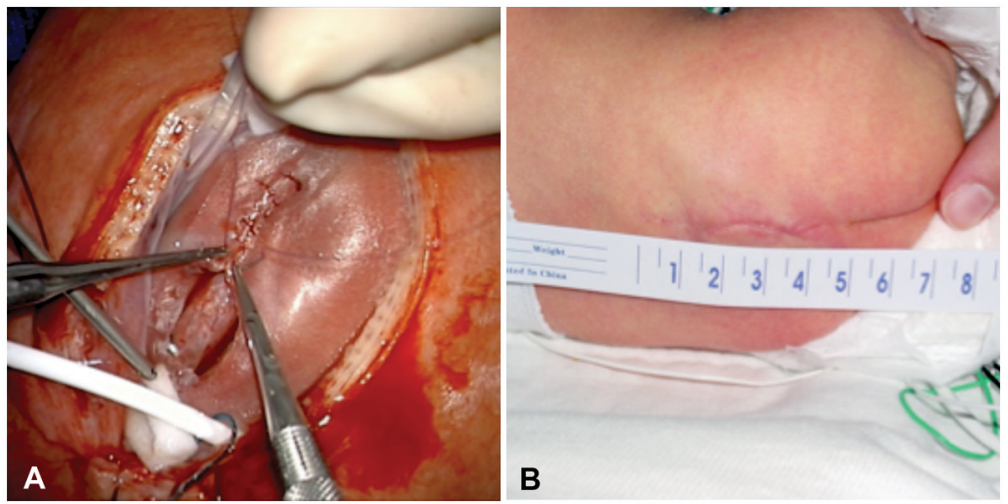

Figure 3. Intraoperative Myelomeningocele Repair

(A): Neural structures are exposed and separated from adjacent tissue. Labeled arrows note lactomer staples on the uterine wall (L), the skin edge (S), the myofascial flap (MF), and the neural placode (NP). (B): The dura is closed over the neural tube. (C): Once the dural closure is completed, surrounding tissue is mobilized for skin closure. 


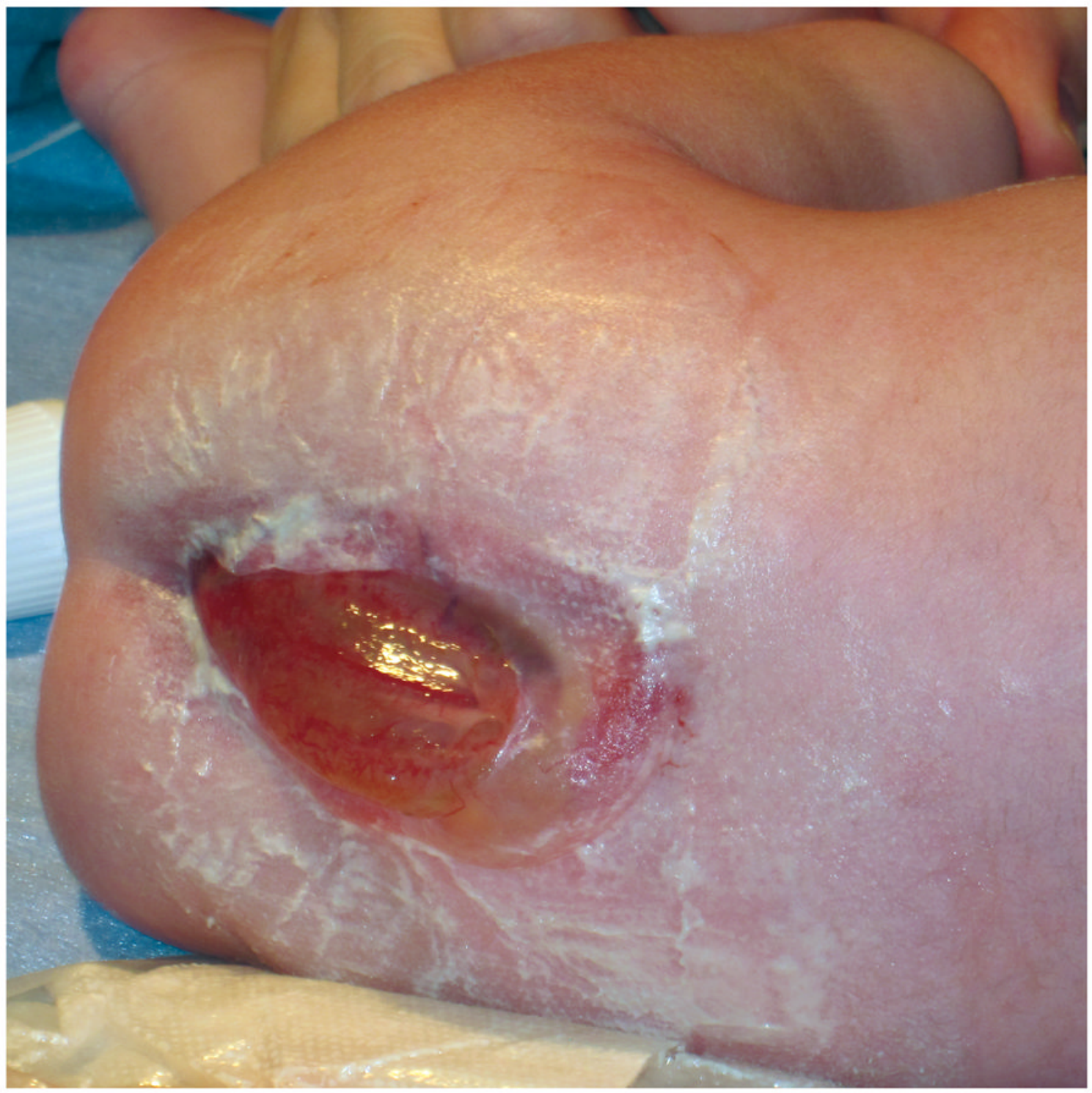

Figure 4. Prenatal fetal myelomeningocele defect primary closure

(A): Primary skin closure is performed when skin tissue can be approximated. (B): A scar over the surgical site remains at birth following a primary skin closure. 

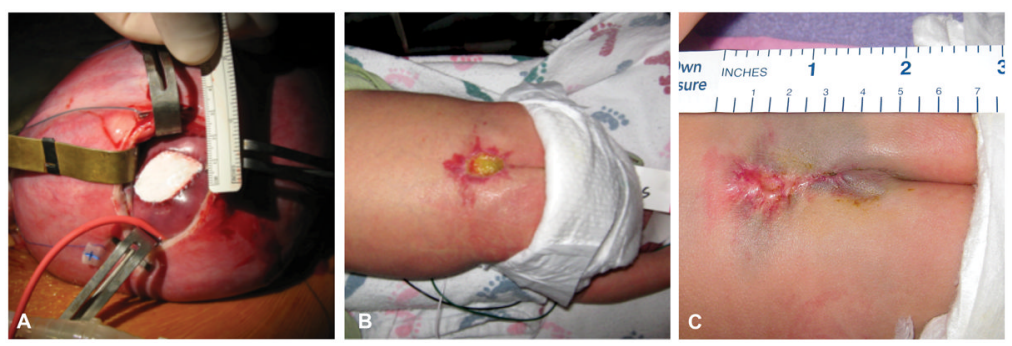

Figure 5. Prenatal fetal myelomeningocele defect closure using a patch

(A): An acellular dermal patch is used when the skin margins cannot be approximated to close the defect. (B): At birth, the patch is often not completely epithelilized, however, the majority of patients form granulation tissue over the patch in one-two weeks and further operative intervention is usually not necessary. (C): Occasionally the patch is completely covered by granulation tissue at birth. 
Table 1

\section{Conditions Associated with Myelomeningocele}

Infants born with myelomeningocele are faced with various life-long disabilities. Although the degree of motor and sensory disability is associated with the level of the vertebral defect, the functional level of neurologic deficit is frequently one or more levels higher than the anatomic defect. Nearly all infants born with a myelomeningocele have supraspinal neurologic manifestations of the disease process.

\footnotetext{
Loss of motor function below level of lesion

Loss of sensation below level of lesion

Bladder and bowel dysfunction

Sexual dysfunction

Cognitive delay

Arnold-Chiari Type II malformation

Hydrocephalus

Tethered cord
} 
Table 2

\section{Obstetrical and Fetal/Neonatal Complications for MOMS Trial Patients}

The rates of maternal and fetal/neonatal complications observed in the prenatal and postnatal repair groups in the Management of Myelomeningocele Study (MOMS) ${ }^{28}$ are listed with corresponding statistical significance. Although other complication outcomes were evaluated, only those determined to be different between the two groups are included in the table. Percentage of complications is noted in parentheses.

\begin{tabular}{|c|c|c|c|}
\hline & Prenatal $\underline{(\mathrm{N}=78)}$ & Postnatal $\underline{(\mathrm{N}=80)}$ & $\underline{\text { P-Value }}$ \\
\hline \multicolumn{4}{|l|}{ Maternal Outcomes } \\
\hline Chorioamniotic membrane separation & $20(26 \%)$ & 0 & $<0.001$ \\
\hline Pulmonary edema & $5(6 \%)$ & 0 & 0.03 \\
\hline Oligohydramnios & $16(21 \%)$ & $3(4 \%)$ & 0.001 \\
\hline Placental abruption & $5(6 \%)$ & 0 & .03 \\
\hline Spontaneous membrane rupture & $36(46 \%)$ & $6(8 \%)$ & $<0.001$ \\
\hline Spontaneous labor & $30(38 \%)$ & $11(14 \%)$ & $<0.001$ \\
\hline Blood transfusion at delivery & $7(9 \%)$ & $1(1 \%)$ & 0.03 \\
\hline Hysterotomy site thin, partial or completely dehisced at delivery & $27(36 \%)$ & N/A & \\
\hline \multicolumn{4}{|l|}{ Fetal Outcomes } \\
\hline Fetal bradycardia during repair & $8(10 \%)$ & 0 & 0.003 \\
\hline Mean gestational age at birth (weeks) & $34.1 \pm 3.1$ & $37.3 \pm 1.1$ & $<0.001$ \\
\hline Mean birth weight (g) & $2383 \pm 688$ & $3039 \pm 469$ & $<0.001$ \\
\hline Respiratory Distress Syndrome & $16(21 \%)$ & $5(6 \%)$ & 0.008 \\
\hline
\end{tabular}


Table 3

Perioperative Considerations for Open Fetal Repair of Myelomeningocele

A detailed summary of perioperative considerations for anesthetic management of open fetal myelomeningocele repair is presented.

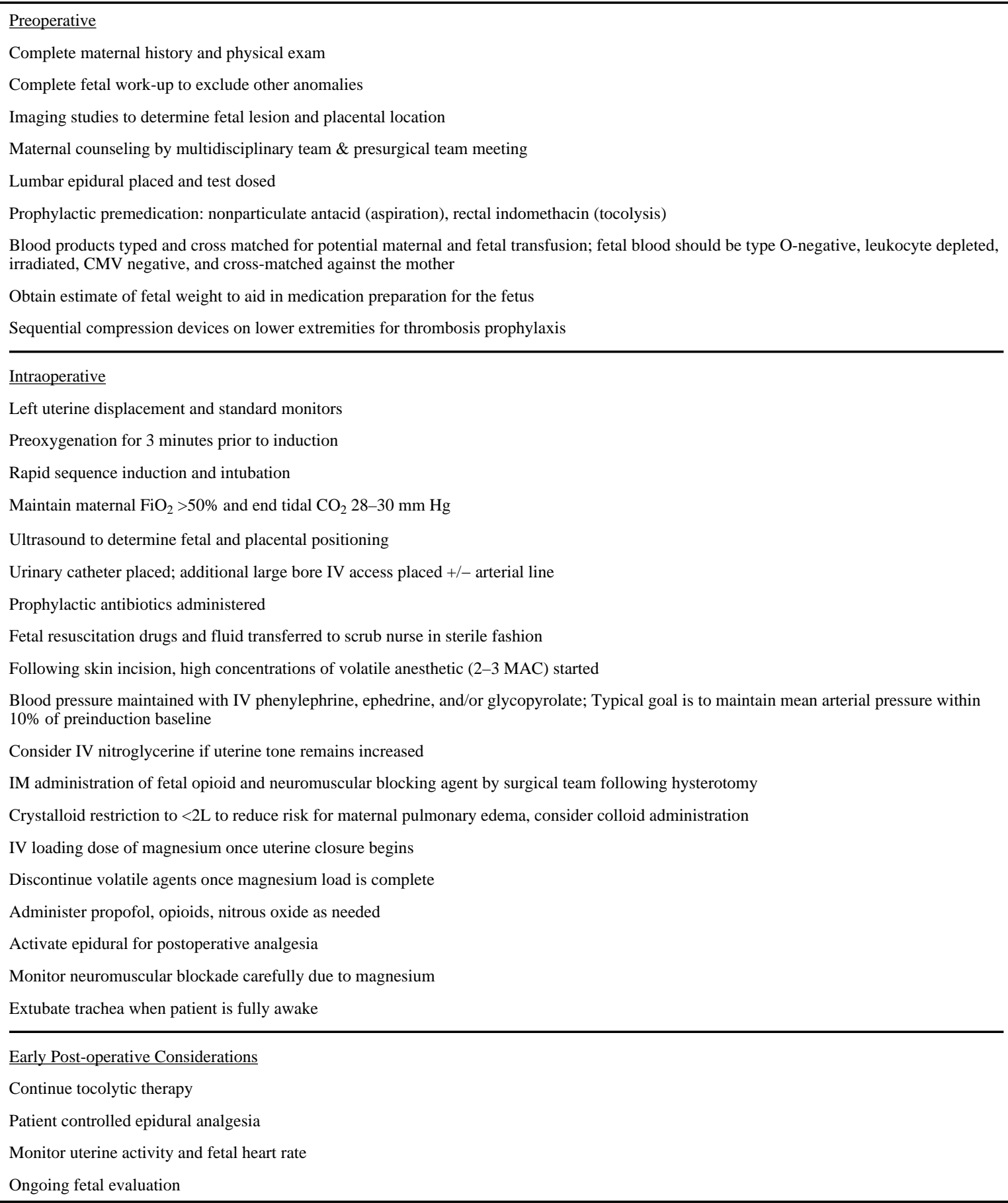

$\mathrm{CO}_{2}=$ carbon dioxide, $\mathrm{CMV}=$ cytomegalovirus, $\mathrm{FiO}_{2}=$ fraction of inspired oxygen, $\mathrm{IM}=$ intramuscular, $\mathrm{IV}=$ intravenous, and $\mathrm{MAC}=$ minimum alveolar concentration. 